\title{
Association of rheumatoid arthritis and its severity with human leukocytic antigen-DRB1 alleles in Kurdish region in North of Iraq
}

\author{
Niaz Albarzinji ${ }^{*}$, Sherzad Ali Ismael ${ }^{2}$ and Dashty Albustany ${ }^{1}$
}

\begin{abstract}
Background: Rheumatoid arthritis is a complex multifactorial chronic disease, the importance of human leukocytic antigen (HLA) as a major genetic risk factor for rheumatoid arthritis was studied worldwide. The objective of this study is to identify the association of HLA-DRB1 subtypes with rheumatoid arthritis and its severity in Kurdish region.

Methods: A case-control study recruited 65 rheumatoid arthritis patients and 100 healthy individuals as control group all over the Kurdistan region/Iraq. Both patient and control groups are genotyped using polymerase chain reaction with sequence specific primer. Anti-CCP antibodies were measured by ELISA test. Rheumatoid factor, C-reactive protein, and disease activity score 28 which measured by DAS- 28 values were calculated. The DAS- 28 was used to assess the clinical severity of the patients.

Results: HLA-DRB1-0404 and HLA-DRB1-0405 frequencies showed a strong association with disease susceptibility $(P<0.001)$. The frequency of HLA-DRB1-0411 and HLA-DRB1-0413 were significantly higher in control group $(P<0.001)$. The frequency of rheumatoid factor and Anti-CCP were significantly higher among shared epitope-positive patients compared to shared epitope-negative patients $(P<0.001)$. Regarding the disease activity by DAS-28, rheumatoid arthritis patients didn't show significant difference between the shared epitope-positive and shared epitopenegative patients.
\end{abstract}

Conclusions: HLA-DR0404 and HLA-DR0405 alleles are related to RA, while HLA-DR1-0411 and HLA-DRB1-0413 protect against RA in the Kurdistan region in the North of Iraq.

Keywords: HLA-DRB1 antigen, Rheumatoid arthritis, Disease susceptibility, Kurdish region, Iraq

\section{Background}

Rheumatoid arthritis (RA) is chronic inflammatory disorder of unknown etiology that affect the joints and other organs in the body, regarding the prevalence of the disease is about of $1 \%$ [1] of total population. It is characterized by pain and chronic inflammatory arthritis, which leads to progressive destruction of both the bone and the cartilage and leading to functional disability [2].

*Correspondence: niazjawad@yahoo.com

${ }^{1}$ Hawler Medical University, Erbil, Iraq

Full list of author information is available at the end of the article
The disease is more common in women than in men with the ration of 3:1. Although the disease can occur at any age but the peak age of onset of the disease is in the 40 s [3]. The genetic and environmental risk factors play key roles in the disease pathogenesis $[1,4]$. The inheritance probability of RA is estimated to be around $60 \%[4$, 5].

One of the most important genetic factor that found to be risk factor for developing RA is human leukocytic antigen (HLA),as showed in many studies that HLA-DR4 is associated with developing RA in different populations [6-11]. Recently, nineteen different allelic 
variants of HLA-DR4 have been found by means of allele specific oligo typing, some of them they are associated with RA in different ethnic groups [6-11]. For example, DRB1*0404 and DRB1*0405 were associated with developing of RA many studies showed that there's strong relationship between HLA-DRB1 and RA [10, 11]. HLA-DRB1 alleles encoding the SE (DRB1*0401, "0404, "0407, "0409 and "0410) are associated with the severity of RA and have been more recently related with production of anti-citrullinated peptide autoantibodies (anti-CCP) [7-9]. Meanwhile the SE negative genotypes (mainly DRB1*0411 and *0413) are proved to be protective against RA susceptibility $[12,13]$.

\section{Methods}

The study is a case-control type, recruited 65 patients diagnosed as RA according to American college of rheumatology [14]. The study started in the April 2019 and lasts for 8 months included 18 male and 47 female patients; the cases collected at the rheumatological consultation clinic in Rizgary teaching hospital. Furthermore, the study recruited 100 healthy individuals as control group which are mainly the medical staff. Both patients and control groups were from Kurdish nation in north of Iraq. An informed consent was obtained from all patients and healthy individuals. Both verbal and written informed consents are taken from participants before their participation in the study.

Blood samples were obtained from all the 65 patients and the 100 healthy control cases; the detection of anti-CCP IgG antibodies was performed using ELISA kit (Euroimmun, Lübeck, Germany). Serum samples presenting results $>18 \mathrm{RU} / \mathrm{mL}$ were considered to be positive for anti-CCP antibodies. Rheumatoid factor, C-reactive protein (CRP) and disease activity score 28 (DAS-28) values were adopted from patients' medical records. The DAS-28 was used to assess the clinical severity of the patients [15]. Genomic DNA of patients with RA $(n=65)$ and healthy controls $(n=100)$ were isolated from peripheral anticoagulated venous blood samples by using the high pure PCR Template Preparation Kit (Roche, Mannheim, Germany). Genotyping of HLA-DRB1 was performed by polymerase chain reaction with sequence-specific primers (PCR-SSP) using Micro SSPT Generic HLA Class II (DRB) (One Lambda Inc., CA, USA). Odds ratio (OR) and 95\% confidence interval $(95 \% \mathrm{CI})$ were calculated to estimate the strengths of the associations. Chi-squared was used in the statistical analysis. Differences were considered to be significant at $\mathrm{P} \leq 0.05$. Statistical Package of Social Sciences (SPSS v22) was used for data analysis.

\section{Results}

The mean \pm SD of age of the cases was $47.4 \pm 10.6$ years and the mean $\pm \mathrm{SD}$ of duration of the disease was $9.5 \pm 3.7$ years. The mean \pm SD of age of the controls was $40.21 \pm$ SD of 10.11 years. All the controls age and gender are matched with the cases. Demographic data and clinical findings of $65 \mathrm{RA}$ patients are diagnosed according to the modified ACR criteria are given in Table 1.

Frequencies of HLA-DRB1 alleles of RA patients and normal individuals with frequency of shared epitope (SE) in RA patients and control group are summarized in Table 2. In RA patients, HLA-DRB1 "0404, "0405 allele frequencies were significantly higher among cases than controls (OR 10.05, 95\% CI 4.04-25.02, $\mathrm{P}=0.001$ ) and (OR 5.05, 95\% CI 2.26-11.27, $\mathrm{P}<0.0001$ ) respectively. In contrast, DRB1 *0411 and "0413 alleles were more frequent in controls which was statistically significant (OR 0.15, 95\% CI 0.07-0.33, P=0.001) and (OR $0.13,95 \%$ CI $0.050-0.36$ ), $\mathrm{P}=0.001$ ), respectively. The allele frequency differences of DRB1*0403, "0407, "0408, "0409, 0410, "0412, "0414, and "0415 was not statistically significant (95\% CI of "16 overlapped). Compared to controls, the frequencies of SE positive alleles (the sum of DRB1"0401, "0404, "0407, "0409 and *0410) were higher significantly in RA patients than the control group (OR 3.41, 95\% CI 2.35-4.95, $\mathrm{P}<0.0001$ ).

Anti-CCP antibody was present in $63.07 \%$ while RF was present in $67.69 \%$ of the RA patients. Frequencies of anti-CCP antibodies and RF were statistically higher in SE-positive patients compared to SE-negative patients (OR 4.93, 95\% CI 1.51-16.08, $\mathrm{P}<0.005)$ and (OR 4.80, 95\% CI 1.48-15.59), $\mathrm{P}<0.006$ ), respectively, Table 3.

Table 1 Demographic and clinical characteristics of patients with rheumatoid arthritis

\begin{tabular}{lc}
\hline Characteristics & RA $(\mathbf{n}=\mathbf{6 5})$ \\
\hline Age, mean $(+,-$ SD) years & $47.4(10.6)$ \\
Disease duration, mean $(+,-$ SD) years & $9.5(3.7)$ \\
Women & $47(72.30 \%)$ \\
Men & $18(27.69 \%)$ \\
RF positive patients & $44(67.69 \%)$ \\
Anti-CCP positive patients & $41(63.07 \%)$ \\
(RP (mg/L) & $25(32.3)$ \\
DAS-28, mean (SD) & $5.1(1.2)$ \\
\hline
\end{tabular}


Table 2 The distribution of HLA-DRB1 allele frequencies in RA patients and controls

\begin{tabular}{|c|c|c|c|c|c|c|}
\hline \multirow[t]{2}{*}{ Genotype_HLA_DRB1 } & \multicolumn{2}{|c|}{$\mathrm{RA}(\mathrm{n}=65)$} & \multicolumn{2}{|c|}{ Control $(n=100)$} & \multirow[t]{2}{*}{ OR (95\%) } & \multirow[t]{2}{*}{$P$ value } \\
\hline & No & $\mathrm{AF}(\%)$ & No & $\mathrm{AF}(\%)$ & & \\
\hline DRB $1 * 0401$ & 5 & 7.89 & 6 & 6 & $1.306(0.38-4.46)$ & 0.670 \\
\hline DRB $1 * 0403$ & 8 & 12.3 & 21 & 21 & $0.52(0.21-1.276)$ & 0.151 \\
\hline DRB $1 * 0404$ & 28 & 43.07 & 7 & 7 & $10.05(4.04-25.02)$ & $<0.001$ \\
\hline DRB $1 * 0405$ & 25 & 38.46 & 11 & 11 & $5.05(2.26-11.27)$ & $<0.001$ \\
\hline DRB1*0407 & 6 & 9.2 & 20 & 20 & $0.40(0.15-1.07)$ & 0.063 \\
\hline DRB1*0408 & 3 & 4.61 & 6 & 6 & $0.75(0.18-3.14)$ & 0.702 \\
\hline DRB1*0409 & 1 & 1.65 & 3 & 3 & $0.50(0.051-4.9)$ & 0.969 \\
\hline $\mathrm{DRB} 1 * 0410$ & 8 & 12.3 & 10 & 10 & $1.26(0.47-3.38)$ & 0.642 \\
\hline DRB1*0411 & 13 & 20 & 61 & 61 & $0.15(0.07-0.33)$ & $<0.001$ \\
\hline $\mathrm{DRB} 1 * 0412$ & 0 & 0 & 5 & 5 & $0.0(0.0-?)$ & 0.157 \\
\hline $\mathrm{DRB} 1 * 0413$ & 5 & 7.69 & 38 & 38 & $0.13(0.050-0.36)$ & $<0.001$ \\
\hline DRB1*0414 & 9 & 13.84 & 12 & 12 & $1.17(0.46-2.97)$ & 0.728 \\
\hline DRB1*0415 & 8 & 12.3 & 19 & 19 & $0.59(0.24-1.46)$ & 0.257 \\
\hline SE positive & 48 & 73.84 & 46 & 46 & $3.31(1.68-6.53)$ & $<0.001$ \\
\hline
\end{tabular}

Shared epitope $* 0401, * 0404, * 0407, * 0409$ and $* 0410$

Values are number (\%) unless otherwise indicated

AF allele frequency, SE positive: the sum of DRB $1 * 0401,{ }^{*} 0404, * 0407, * 0409$ and $* 0410$, alleles; OR odds ratio; $95 \% \mathrm{Cl}$ confidence interval at $95 \%$. HLA frequencies observed in patients and controls were compared using the chi-square test. Differences were considered significant at $\mathrm{P}<0.05$

Table 3 Association of HLA-DRB1 shared epitopes alleles with anti-CCP and rheumatoid factor antibodies in rheumatoid arthritis patients $(n=65)$

\begin{tabular}{llcll}
\hline SE status & SE positive $(\mathbf{n}=\mathbf{4 8}) \mathbf{n o .}(\mathbf{\%})$ & SE negative $(\mathbf{n}=\mathbf{1 7})$ no. (\%) & OR (95\%) & P value \\
\hline Anti-CCP positive & $35(72.81 \%)$ & $6(35.29 \%)$ & $4.93(1.51-16.08)$ & 0.005 \\
Anti-CCP negative & $13(27.08 \%)$ & $11(64.70 \%)$ & $0.20(0.06-0.65)$ & 0.005 \\
RF positive & $37(77.08 \%)$ & $7(41.17 \%)$ & $4.80(1.48-15.59)$ & 0.006 \\
RF negative & $11(22.91 \%)$ & $10(58.82 \%)$ & $0.20(0.064-0.67)$ & 0.006 \\
\hline
\end{tabular}

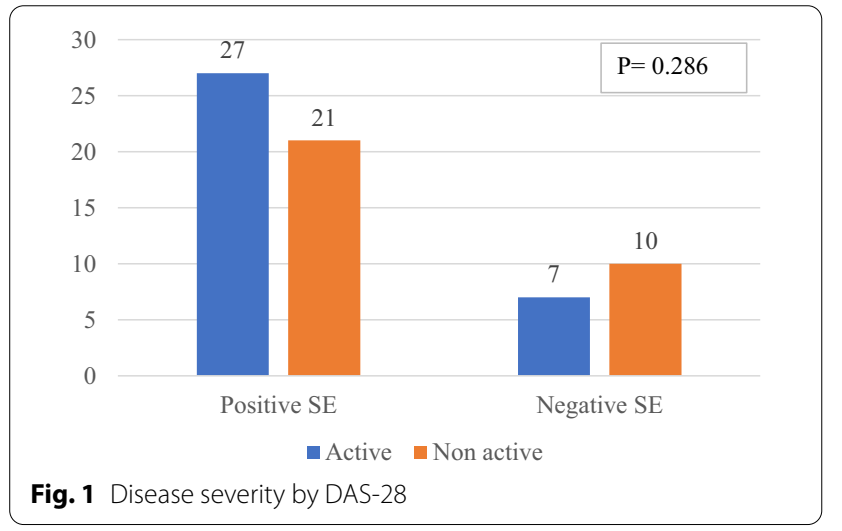

Disease severity presented by DAS-28 values showed no significance difference between SE negative and SE positive RA patients, Fig. 1.

\section{Discussion}

Although the etiology of RA is unclear, but the genetic susceptibility of RA in association with HLA-DR is well known in different ethnic groups such as DR4 in Caucasian, American black, Chinese, and Japanese patients with RA, and DR1 in Asian Indian and Ashkenazi Jewish patients [16-18].

In our study, we have found that the DRB1*0404 and HLA-DRB1*0405 allele to be strongly associated with RA in Kurdish patients. A similar finding was reported in Japanese [10], Singaporean Chinese [11], in Morocco [19] and Zahedan southeast Iran [20], on the other hand, Peruvian [21] and Mexican American [22] populations showed no significant correlation between HLADRB1*0404 and RA susceptibility.

The current study showed that HLA-DRB1*0411 and HLA-DRB1*0413 alleles were more frequent in controls than the patients; these alleles were regarded as 
protective effect against RA. The same result has been reported in several reviews $[5,12,23,24]$ and revealed in different populations. The HLA-DRB1*0411 in Peruvian [25], and Tunisians [26], while HLA-DRB1*0413 showed protective effect against RA in TURKISH [27, 28], Asians [29], and Slovakians [30]. Moreover, HLADRB1*0406 showed protective effect in Iranians [20], Saudians [31] and DRB1*0408 in Mexican Americans [2].

The relation between the SEs and the severity of RA has not been clearly understood yet [32] in many studies that done in Northern Europe [33], Netherlands [34], Northern Italy [35], and Caucasians [35, 36]; showed that DRB1*0401 allele is indicated to increase the severity of RA whereas DRB1*0405 allele is mainly in Korea [37]. But in our study showed no significant correlation of disease severity which assessed by mean DAS-28 values between the SE positive and SE negative patients. This may be due to the small number of patients in our study. These results agree with studies carried out in Turkey [28] and Greece [38]. Moreover, our study agree with previously reported relationship of SE positive alleles in the productions of anti-CCP and RF sero-positivity [5, 12, 34, 39].

\section{Conclusions}

HLA-DRB1*0404, and *0405 alleles were proved in our study to be associated with RA while HLA-DRB1*0411 and "0413 were showed to be protective alleles against RA in Kurdish population. No significance was observed between SEs alleles and the severity of RA, both Anti-CCP antibody and rheumatoid factor were significantly higher in SE-positive patients compared to SE-negative patients.

\section{Abbreviations \\ RA: Rheumatoid arthritis; HLA: Human leukocytic antigen; DAS-28: Disease activity score 28; CRP: C-reactive protein; SPSS v22: Statistical Package of Social Sciences version 22.}

\section{Acknowledgements}

Not applicable.

\section{Data access and responsibility}

The first investigator, Niaz Albarzinji, had full access to all of the data in the study and takes responsibility for the integrity of the data and the accuracy of the data analysis.

\section{Authors' contributions}

Dr. NA confirms responsibility for the following: study conception and design, data collection and final draft revision. Dr. SAI did the analysis and interpretation of results and manuscript preparation. Dr. DA has revised the first draft and finalized the questionnaire. All authors read and approved the final manuscript.

\section{Funding}

The study is not funded by any institution or agency.

\section{Availability of data and materials}

The datasets used and analyzed during the current study are available from the corresponding author on reasonable request. The blood samples are stored at the center laboratory of Erbil until the end of the study then the specimen containers were discarded into special disinfectant-filled containers.

\section{Declarations}

\section{Ethics approval and consent to participate}

All the methods used in this study were carried out in accordance with relevant guidelines and regulations in accordance with the Declaration of Helsinki. The protocol of the study was approved by the research Ethics Committee of College of Medicine of Hawler Medical University with an approval meeting code of 9 and paper code of 12 at 1/ 04/2019. We confirm that all methods were performed in accordance with the relevant guidelines and regulations. Participants who agreed to participate in the study were informed about the study aims and objectives and also are requested to sign an institutional written consent form in their native language. Both verbal and written informed consents are taken from participants before their participation in the study; in the written consent, the purpose of the research, the length of time for participation, a detailed procedure was written for participants, any possible discomforts and also any possible benefits from participation and information about any alternative procedures that might benefit the research subject are clearly explained to all the participants. In addition, it is stated that the participants are voluntarily participate and can withdraw from the study at any time if they decided.

\section{Consent for publication}

The study data didn't contain any individual person's data in any form (including any individual details, images or videos). The privacy of the individual's data is protected by encoding them. All data in electronic format are stored on the first author's personal computer. Only the first author has an access to these data.

\section{Competing interests}

The authors declare that they have no competing interests.

\section{Author details}

${ }^{1}$ Hawler Medical University, Erbil, Iraq. ${ }^{2}$ Kurdistan Board of Medical Specialties, Erbil, Iraq.

Received: 17 April 2021 Accepted: 30 July 2021

Published online: 12 January 2022

References

1. Kochi Y, Suzuki A, Yamada R, Yamamoto K. Genetics of rheumatoid arthritis: underlying evidence of ethnic differences. J Autoimmune. 2009;32(3-4):158-62.

2. Neumann E, Lefèvre S, Zimmermann B, Gay S, Müller-Ladner U. Rheumatoid arthritis progression mediated by activated synovial broblasts. Trends Mol Med. 2010;16(10):458-68.

3. Suchomel P, Buchvald P, Choutka O. Rheumatoid arthritis. In: Suchomel P, Choutka O, editors. Reconstruction of upper cervicalspine and craniovertebral junction. Berlin: Springer; 2011. p. 235-46.

4. Hoovestol RA, Mikuls TR. Environmental exposures and rheumatoid arthritis risk. Curr Rheumatol Rep. 2011;13:431-9.

5. de Vries R. Genetics of rheumatoid arthritis: time for a change! Curr Opin Rheumatol. 2011;23(3):227-32.

6. Gao X, Olsen NJ, Pincus T, Stastny P. HLA-DR alleles with naturally occurring amino acid substitutions and risk for development of rheumatoid arthritis. Arthritis Rheum. 1990;33:939-46.

7. Gregersen PK, Shen M, Song Q, et al. Molecular diversity of HLA-DR4 haplotypes. Proc Natl Acad Sci USA. 1986;83:2542-6.

8. Molkentin J, Gregersen PK, Xingyu L, et al. Molecular analysis of HLA-DR,3 and DQ, B polymorphism in Chinese with rheumatoid arthritis. Ann Rheum Dis. 1993;52:610-2.

9. Segalias J, Li EK, Cohen MG, Wong RWS, Potter PK, So AK. linkage between rheumatoid arthritis susceptibility and the presence of HLA-DR4 
and DR,3 allelic third hypervariable region sequences in southern Chinese persons. Arthritis Rheum. 1992;35:163-7.

10. Okubo H, Itou K, Tanaka S, Watanabe N, Kashiwagi N, Obata F. Analysis of the HLA-DR gene frequencies in Japanese cases of juvenile rheumatoid arthritis and rheumatoid arthritis by oligonucleotide DNA typing. Rheumatol Int. 1993;13:65-9.

11. Chan SH, Lin YN, Wee GB, Koh WH, BoeyM L. HLA class 2 genes in Singaporean Chinese rheumatoid arthritis. Br J Rheumatol. 1994;33:713-7.

12. Bax M, van Heemst J, Huizinga TW, Toes RE. Genetics of rheumatoid arthritis: what have we learned? Immunogenetics. 2011;63(8):459-66.

13. Gibert M, Balandraud N, Touinssi M, Mercier P, Roudier J, Reviron D. Functional categorization of HLA-DRB1 alleles in rheumatoid arthritis: the protective effect. Hum Immunol. 2003;64(10):930-5.

14. Amett FC, Edworthy SM, Bloch DA, et al. The American Rheumatism Association 1987 revised criteria for the classification of rheumatoid artritis. Arthritis Rheum. 1988:31:114-22.

15. Prevoo MLL, Van't Hof MA, Kuper HH, van Leeuwen MA, van De Putte LBA, van Riel PL. Modified disease activity scores that include twentyeight-joint counts development and validation in a prospective longitudinal study of patients with rheumatoid arthritis. Arthritis Rheum. 1995;38(1):44-8

16. Stastny P. Joint report. Rheumatoid arthritis. In: Terasaki PI, ed. Histocompatibdity testing 1980. Los Angeles: UCLA Tissue Typing Laboratory, 1980; 681-6.

17. Wordsworth BP, Bell Jl. The immunogenetics of rheumatoid arthritis. In: McDevitt H, editor. Seminars in immunopathology, vol. 14. Berlin: Springer; 1992. p. 59-78.

18. Wordsworth BP, Stedeford J, Rosenberg WMC, Bell JI. Limited heterogeneity of the class II contribution to susceptibility to rheumatoid arthritis is suggested by positive associations with HIA-DR4, DRI and DRw1O. Br J Rheumatol. 1991:30:178-80

19. Atouf O, Benbouazza K, Brick C, Bzami F, Bennani N, Amine B, et al. HLA polymorphism and early rheumatoid arthritis in the Moroccan population. Joint Bone Spine. 2008;75(5):554-8.

20. Sandoughi M, Fazaeli A, Bardestani G, Hashemi M. Frequency of HLADRB1 alleles in rheumatoid arthritis patients in Zahedan, southeast Iran. Ann Saudi Med. 2011;31(2):171-3.

21. Castro F, Acevedo E, Ciusani E, Angulo JA, Wollheim FA, SandbergWollheim M. Tumour necrosis factor microsatellites and HLADRB ${ }^{*}$, HLA-DQA 1*, and HLA-DQB1* alleles in Peruvian patients with rheumatoid arthritis. Ann Rheum Dis. 2001;60(8):791-5.

22. del Rincon I, Escalante A. HLA-DRB1 alleles associated with susceptibility or resistance to rheumatoid arthritis, articular deformities, and disability in Mexican Americans. Arthritis Rheum. 1999;42(7):1329-38.

23. Perricone C, Ceccarelli F, Valesini G. An overview on the genetic of rheumatoid arthritis: a never-ending story. Autoimmun Rev. 2011;10(10):599-608.

24. Feitsma AL, van der Helm-van Mil AHM, Huizinga TWJ, de Vries RRP, Toes REM. Protection against rheumatoid arthritis by HLA: nature and nurture. Ann Rheum Dis. 2008;67(Suppl 3):i61-3.

25. Castro F, Acevedo E, Ciusani E, Angulo JA, Wollheim FA, Sandberg-Wollheim M. Tumour necrosis factor microsatellites and HLADRB, HLA-DQA1, and HLA-DQB1 alleles in Peruvian patients with rheumatoid arthritis. Ann Rheum Dis. 2001;60(8):791-5.
26. Dhaouadi T, Sfar I, Abdelmoula L, Bardi R, Jendoubi-Ayed S, Makhlouf $M$, et al. Association of specific amino acid sequence (QRRAA) of HLADRB1*0405 with rheumatoid arthritis in a Tunisian population. Arch Inst Pasteur Tunis. 2010;87(1-2):53-9.

27. Uçar F, Karkucak M, Alemdaroglu E, Capkin E, Yücel B, Sönmez M, et al. HLA-DRB1 allele distribution and its relation to rheumatoid arthritis in eastern Black Sea Turkish population. Rheumatol Int. 2012;32:1003-7.

28. Kinikli G, Ates A, Turgay M, Akay G, Kinikli S, Tokgoz G. HLADRB1 genes and disease severity in rheumatoid arthritis in Turkey. Scand J Rheumatol. 2003;32(5):277-80.

29. Jun KR, Choi SE, Cha CH, Oh HB, Heo YS, Ahn HY, et al. Meta-analysis of the Association between HLA-DRB1 allele and rheumatoid arthritis susceptibility in Asian populations. J Korean Med Sci. 2007;22(6):973.

30. Stark K, Rovensky J, Blazickova S, Grosse-Wilde H, Ferencik S, Hengstenberg $C$, et al. Association of common polymorphisms in known susceptibility genes with rheumatoid arthritis in a Slovak population using osteoarthritis patients as controls. Arthritis Res Ther. 2009;11(3):R70.

31. Al-Swailem R, Al-Rayes H, Sobki S, Arfin M, Tariq M. HLA-DRB1 association in Saudi rheumatoid arthritis patients. Rheumatol Int. 2006:26(11):1019-24.

32. Gorman JD, Criswell LA. The shared epitope and severity of rheumatoid arthritis. Rheum Dis Clin N Am. 2002;28(1):59-78.

33. Gorman JD, Lum RF, Chen JJ, Suarez-Almazor ME, Thomson G, Criswell LA. Impact of shared epitope genotype and ethnicity on erosive disease: a meta-analysis of 3,240 rheumatoid arthritis patients. Arthritis Rheum. 2004;50(2):400-12.

34. van Gaalen FA, van Aken J, Huizinga TW, Schreuder GM, Breedveld FC, Zanelli E, et al. Association between HLA class II genes and autoantibodies to cyclic citrullinated peptides (CCPs) influences the severity of rheumatoid arthritis. Arthritis Rheum. 2004;50(7):2113-21.

35. Salvarani C, Macchioni PL, Mantovani W, Bragliani M, Collina E, Cremonesi T, et al. HLA-DRB1 alleles associated with rheumatoid arthritis in Northern Italy: correlation with disease severity. Br J Rheumatol. 1998;37(2):165-9.

36. Mewar D, Marinou I, Coote AL, Moore DJ, Akil M, Smillie D, et al. Association between radiographic severity of rheumatoid arthritis and shared epitope alleles: differing mechanisms of susceptibility and protection. Ann Rheum Dis. 2008;67(7):980-3.

37. Fries JF, Wolfe F, Apple R, Erlich H, Bugawan T, Holmes T, et al. HLA-DRB1 genotype associations in 793 white patients from a rheumatoid arthritis inception cohort: frequency, severity, and treatment bias. Arthritis Rheum. 2002;46(9):2320-9.

38. Boki KA, Drosos AA, Tzioufas AG, Lanchbury JS, Panayi GS, Moutsopoulos HM. Examination of HLA-DR4 as a severity marker for rheumatoid arthritis in Greek patients. Ann Rheum Dis. 1993;52(7):517-9.

39. Louzada-Junior P, Freitas MVC, Oliveira RDR, Deghaide NHS, Conde RA, Bertolo MB, et al. A majority of Brazilian patients withrheumatoid arthritis HLA-DRB1 alleles carry both the HLA-DRB1 shared epitope and anticitrunillated peptide antibodies. Braz J Med Biol Res. 2008;41:493-9.

\section{Publisher's Note}

Springer Nature remains neutral with regard to jurisdictional claims in published maps and institutional affiliations.

Ready to submit your research? Choose BMC and benefit from:

- fast, convenient online submission

- thorough peer review by experienced researchers in your field

- rapid publication on acceptance

- support for research data, including large and complex data types

- gold Open Access which fosters wider collaboration and increased citations

- maximum visibility for your research: over 100M website views per year

At BMC, research is always in progress.

Learn more biomedcentral.com/submissions 